\section{Collaborative care for depression in primary care}

\author{
Making sense of a complex intervention: systematic review \\ and meta-regression
}

\author{
PETER BOWER, SIMON GILBODY, DAVID RICHARDS, JANINE FLETCHER \\ and ALEX SUTTON
}

\begin{abstract}
Background The management of depression in primary care is a significant issue for health services worldwide.

'Collaborative care' interventions are effective, but little is known about which aspects of these complex interventions are essential.
\end{abstract} 'active ingredients' in collaborative care models for depression in primary care.

\section{Method Studies were identified using systematic searches of electronic databases. The content of collaborative care interventions was coded, together with outcome data on antidepressant use and depressive symptoms. Meta- regression was used to examine relationships between intervention content and outcomes.}

\section{Results There was no significant predictor of the effect of collaborative care on antidepressant use. Key predictors of depressive symptom outcomes included systematic identification of patients, professional background of staff and specialist supervision.}

Conclusions Meta-regression may be useful in examining 'active ingredients' in complex interventions in mental health.

Declaration of interest None.
Depression is prevalent in primary care, but current management is suboptimal (Simon \& Von Korff, 1995). There is increasing evidence of the effectiveness of 'collaborative care' (Gilbody et al, 2003), a multifaceted organisational intervention involving new staff and ways of working (Von Korff \& Goldberg, 2001). However, collaborative care interventions vary in content and intensity, and it is unclear which aspects are crucial determinants of effectiveness (the 'active ingredients'). Most of the current collaborative care literature derives from the USA, and designing collaborative care interventions for use in other settings requires an understanding of these 'active ingredients'.

Collaborative care is an example of a complex intervention, involving a number of separate mechanisms, where the 'active ingredient' is difficult to specify (Campbell et al, 2000). If different collaborative care interventions vary in their inclusion of 'active ingredients', then this should lead to significant variation in outcomes. Such variation in outcomes in a meta-analysis is described as statistical heterogeneity. Meta-regression is a method used to explore statistical heterogeneity in metaanalysis (Sutton et al, 1998; Thompson \& Higgins, 2002).

A phased approach to the development of complex interventions has been proposed (Campbell et al, 2000). Modelling of complex interventions, where the 'active ingredients' are explored, is a critical step in the phased model prior to further trials. However, there are relatively few examples of the phased model in the literature (Bradley et al, 1999; Campbell et al, 2000; Medical Research Council, 2000; Loeb, 2002) and a lack of consensus as to the optimal modelling methods.

The authors are developing and testing a collaborative care intervention in the UK using the phased approach, and used meta-regression to examine the relationship between the content of collaborative care interventions and outcomes, to identify 'active ingredients' and thus assist in the design of a UK collaborative care model for the care of depression.

\section{METHOD}

\section{Data sources}

We based our meta-regression on a systematic review. A published systematic review of organisational interventions in primary care mental health completed by S.G. was used as the initial source of studies (Gilbody et al, 2003); this review included collaborative care as well as other types of organisational interventions used to improve the management of depression. Searches included Medline, EMBASE, CINAHL, PsycINFO, the Cochrane Library and the Database of Abstracts of Reviews of Effectiveness (DARE), and were run from the inception date of each database to 2003. We updated the comprehensive search strategies from this review (without language restriction) to June 2004 to find recent studies, and then conducted a second update to November 2005 (Fig. 1). Details of the exact search methods and a table of excluded studies are available from the authors upon request. From this comprehensive database, we then identified the subset of collaborative care studies.

\section{Inclusion criteria}

The population of interest was patients with depressive symptoms or diagnosed depressive disorders in primary care settings. Primary care was defined as the provision of medical care by professionals who provide first contact and ongoing care to patients, regardless of the patient's age, gender or presenting problem.

Although we have published a broad typology of models of quality improvement which includes collaborative care (Bower \& Gilbody, 2005), developing precise inclusion criteria for such complex interventions is more problematic, because by definition it is not clear a priori which mechanisms have to be in place in order to define an intervention as 'collaborative care'. Therefore, any definition is potentially arbitrary, reflected by published reviews of collaborative care that disagree on which studies and interventions are included and excluded (Von Korff \& Goldberg, 2001; Gilbody et al, 2003; Bijl et al, 2004). 


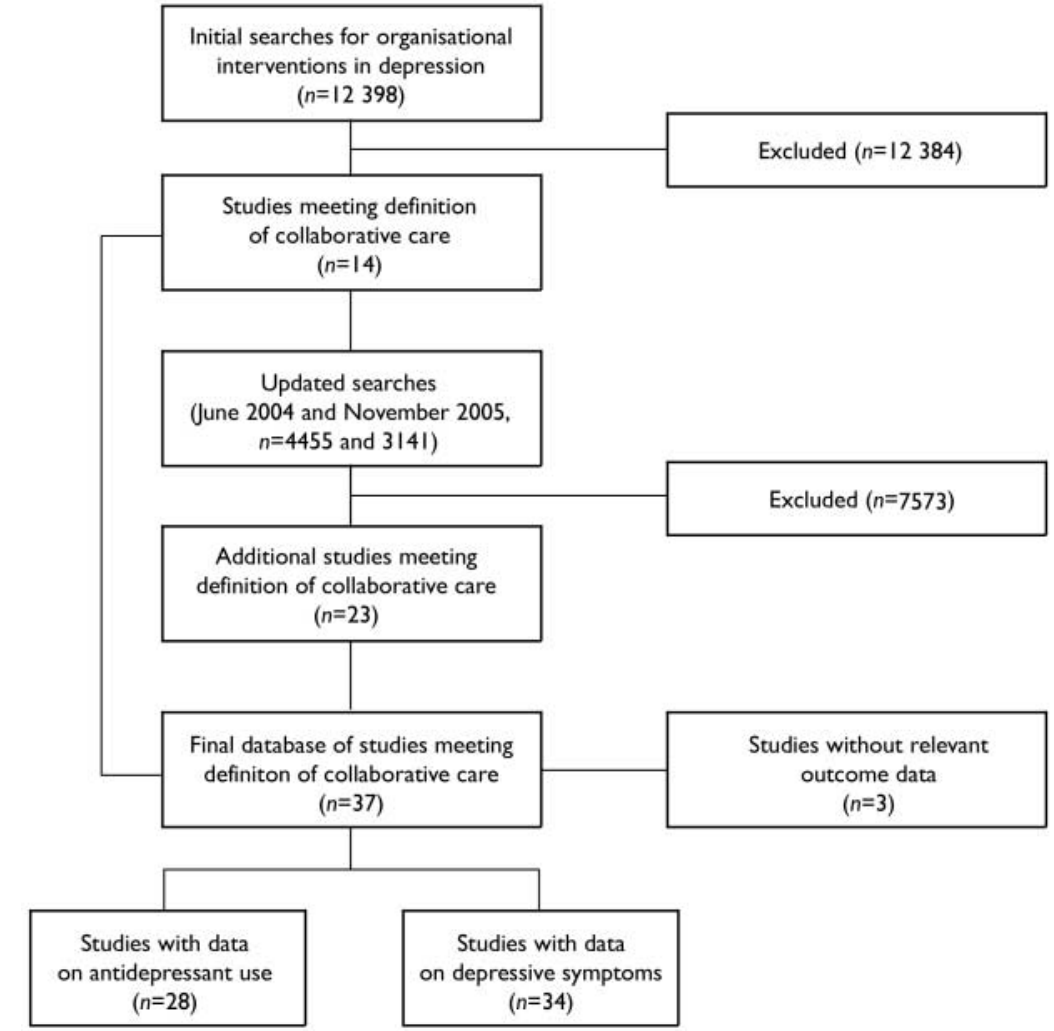

Fig. I QUOROM (Quality of Reporting Meta-analyses) flow diagram.

The purpose of the study was to examine the relationship between variation in the interventions within collaborative care studies, and outcomes. Therefore, we used a broad definition, and defined 'collaborative care' as a multifaceted organisational intervention, which could include a number of components:

(a) the introduction of a new role (case manager) into primary care, to assist in the management of patients with depression through structured and systematic delivery of interventions;

(b) the introduction of mechanisms to foster closer liaison between primary care clinicians and mental health specialists (including case managers) around individual patient care;

(c) the introduction of mechanisms to collect and share information on the progress of individual patients.

We excluded educational and training interventions and the provision of brief psychological therapy where these were the sole intervention and were not supported by other enhancements of care outlined above. The full list of studies is given in Table 1.

\section{Data extraction}

\section{Content of collaborative care}

We initially tested published coding schemes relating to quality improvement (Weingarten et al, 2002; Bero et al, 2006), but these lacked the detail to capture the specific issues of relevance to collaborative care. Therefore, a basic coding frame was developed on the basis of the 'prototypical' collaborative care model, described in terms of the three roles potentially involved in patient care: primary care provider, mental health specialist and case manager (Katon et al, 2001b). Variables were created relating to the professional background of each worker and additional intervention-specific training. These codes were then supplemented by variables describing the potential interprofessional relationships (e.g. specialist supervision of the case manager, and case manager feedback of information to the primary care provider). Because professional-patient contact within collaborative care is focused on the case manager-patient relationship, we added variables relating to the intensity and nature of that contact. Finally, we added three variables related to the characteristics of the patients and study setting (see Appendix).

After piloting the data extraction among the team, data from each study were extracted by two different members of the research team working independently. There was no formal measurement of reliability, but disagreements were few and were resolved by discussion. Owing to inconsistent reporting of data in the published papers we were only able to extract comprehensive data on 8 of the original 27 variables (see Table 2 ).

Concealment of allocation is the quality attribute with the best evidence for an association with outcomes (Schultz \& Grimes, 2002), and we extracted data on concealment to test whether outcomes were related to study quality.

\section{Intervention outcomes}

Collaborative care interventions often seek to improve adherence to antidepressant medication, and the first outcome measure was changes in measures of antidepressant use. Most studies reported data in dichotomous form, e.g. the proportion of patients taking antidepressants or meeting standardised guidelines for antidepressant use.

The second outcome measure was reduction in depressive symptoms. A wide variety of outcomes were reported at a number of different time points. Because the meta-regression required as large a sample of studies as possible for reliable analysis (Thompson \& Higgins, 2002), we restricted the analysis to short-term outcomes (approximately 6 months after randomisation), as these outcomes were by far the most frequently reported. Where alternative measures of depressive outcomes were reported within the same study, the data extracted were chosen on the basis of an a priori decision rule which extracted any identified primary outcome first, and then prioritised observer-rated scales over self-report measures where available.

We extracted all measures of antidepressant use as dichotomous outcomes, analysed using odds ratios. Measures of depressive symptoms included a mix of dichotomous and continuous outcomes. We translated continuous measures to a standardised effect size, i.e. the mean of the intervention group minus the mean of the control group, divided by the pooled standard deviation. We translated outcomes reported as dichotomous variables 
Table I Studies included in the review

\begin{tabular}{|c|c|c|c|c|c|c|c|}
\hline Study & Reference & Setting & $\begin{array}{l}\text { Unit of } \\
\text { randomisation }\end{array}$ & $\begin{array}{l}\text { Sample } \\
\text { size } \\
n\end{array}$ & Patient population & $\begin{array}{c}\text { Antidepressant } \\
\text { use data? }\end{array}$ & $\begin{array}{c}\text { Depressive } \\
\text { symptoms data? }\end{array}$ \\
\hline Adler 2004 & Adler et al (2004) & USA & Patient & 533 & $\begin{array}{l}\text { Adults with major depression } \\
\text { or dysthymia }\end{array}$ & Yes & Yes \\
\hline Akerblad 2003 & Bungay et al (2004) & Sweden & General practitioner & 1031 & $\begin{array}{l}\text { Adults with major depression } \\
\text { and an indication for } \\
\text { antidepressants }\end{array}$ & Yes & Yes \\
\hline Araya 2003 & Araya et al (2003) & Chile & Patient & 240 & $\begin{array}{l}\text { Adult women with major } \\
\text { depression }\end{array}$ & Yes & Yes \\
\hline $\begin{array}{l}\text { Blanchard } \\
1995\end{array}$ & Blanchard et al (1995) & UK & Patient & 96 & $\begin{array}{l}\text { Elderly people with depres- } \\
\text { sion warranting clinical } \\
\text { intervention }\end{array}$ & Yes & Yes \\
\hline Brook 2003 & Brook et al $(2003 a, b)$ & $\begin{array}{l}\text { The } \\
\text { Netherlands }\end{array}$ & Patient & 147 & $\begin{array}{l}\text { Adults with depressive } \\
\text { complaints, prescribed new } \\
\text { antidepressant }\end{array}$ & No & Yes \\
\hline Bruce 2004 & $\begin{array}{l}\text { Coyne et al (2001); } \\
\text { Bruce et al (2004) }\end{array}$ & USA & Practice & 598 & $\begin{array}{l}\text { Elderly people with major } \\
\text { depression, dysthymia and } \\
\text { minor depression }\end{array}$ & Yes & Yes \\
\hline Callahan 1994 & Callahan et al (1994) & USA & Practice & 175 & $\begin{array}{l}\text { Elderly people with newly } \\
\text { diagnosed depression }\end{array}$ & Yes & Yes \\
\hline Capoccia 2004 & $\begin{array}{l}\text { Boudreau et al (2002); } \\
\text { Capoccia et al (2004) }\end{array}$ & USA & Patient & 74 & $\begin{array}{l}\text { Adults with depression, } \\
\text { prescribed a new } \\
\text { antidepressant }\end{array}$ & Yes & Yes \\
\hline Coleman 1999 & Coleman et al (1999) & USA & Practice & 169 & Frail elderly people & No & Yes \\
\hline Datto 2003 & Datto et al (2003) & USA & Practice & 61 & $\begin{array}{l}\text { Adults with depressive } \\
\text { symptoms }\end{array}$ & No & Yes \\
\hline Dietrich 2004 & $\begin{array}{l}\text { Dietrich et al } \\
(2004 a, b)\end{array}$ & USA & Practice & 405 & $\begin{array}{l}\text { Adults with major depression } \\
\text { and dysthymia, starting/ } \\
\text { changing treatment }\end{array}$ & Yes & Yes \\
\hline Finley 1999 & $\begin{array}{l}\text { Finley et al } \\
(1999,2003)\end{array}$ & USA & Patient & 125 & $\begin{array}{l}\text { Adults with current major } \\
\text { depression, prescribed a new } \\
\text { antidepressant }\end{array}$ & Yes & Yes \\
\hline Hunkeler 2000 & Hunkeler et al (2000) & USA & Patient & 302 & $\begin{array}{l}\text { Adults with major depression } \\
\text { or dysthymia, prescribed a } \\
\text { new antidepressant }\end{array}$ & Yes & Yes \\
\hline Katon 1995 & $\begin{array}{l}\text { Katon et al (1995); } \\
\text { Von Korff et al (1998) }\end{array}$ & USA & Patient & 217 & $\begin{array}{l}\text { Adults with depression, } \\
\text { prescribed a new anti- } \\
\text { depressant }\end{array}$ & Yes & Yes \\
\hline Katon 1996 & $\begin{array}{l}\text { Katon et al (1996); } \\
\text { Von Korff et al (1998) }\end{array}$ & USA & Patient & 153 & $\begin{array}{l}\text { Adults with depression, } \\
\text { prescribed a new anti- } \\
\text { depressant }\end{array}$ & Yes & Yes \\
\hline Katon 1999 & $\begin{array}{l}\text { Katon et al (1999); } \\
\text { Simon et al (200la) }\end{array}$ & USA & Patient & 228 & $\begin{array}{l}\text { Adults on antidepressants, } \\
\text { at high risk of persistent } \\
\text { depression, recurrent } \\
\text { depression or dysthymia }\end{array}$ & Yes & Yes \\
\hline Katon 200I & $\begin{array}{l}\text { Katon et al (200la), } \\
\text { Simon et al (2002) }\end{array}$ & USA & Patient & 386 & $\begin{array}{l}\text { Adults, prescribed a new } \\
\text { antidepressant, at high risk of } \\
\text { relapse }\end{array}$ & Yes & Yes \\
\hline Katon 2004 & $\begin{array}{l}\text { Katon et al } \\
(2003,2004)\end{array}$ & USA & Patient & 329 & $\begin{array}{l}\text { Adults with diabetes with } \\
\text { depressive symptoms }\end{array}$ & No & Yes \\
\hline
\end{tabular}


Table I (Continued)

\begin{tabular}{|c|c|c|c|c|c|c|c|}
\hline Study & Reference & Setting & $\begin{array}{l}\text { Unit of } \\
\text { randomisation }\end{array}$ & $\begin{array}{l}\text { Sample } \\
\text { size } \\
n\end{array}$ & Patient population & $\begin{array}{c}\text { Antidepressant } \\
\text { use data? }\end{array}$ & $\begin{array}{l}\text { Depressive } \\
\text { symptoms data? }\end{array}$ \\
\hline Katzelnick 2000 & $\begin{array}{l}\text { Katzelnick et al (2000); } \\
\text { Simon et al (200lb) }\end{array}$ & USA & Practice & 407 & $\begin{array}{l}\text { Adults, high users of services, } \\
\text { with depressive symptoms }\end{array}$ & Yes & Yes \\
\hline Mann 1998 & Mann et al (1998) & UK & Patient & 419 & Adults with depression & Yes & Yes \\
\hline Oslin 2003 & Oslin et al (2003) & USA & Physician & 97 & $\begin{array}{l}\text { Adults with depression or } \\
\text { dysthymia, at risk drinking }\end{array}$ & No & Yes \\
\hline Peveler 1999 & Peveler et al (1999) & UK & Patient & 160 & $\begin{array}{l}\text { Diagnosis of depression, } \\
\text { prescribed a new anti- } \\
\text { depressant }\end{array}$ & Yes & Yes \\
\hline Rickles 2003 & Rickles (2003) & USA & Patient & 63 & $\begin{array}{l}\text { Prescribed a new anti- } \\
\text { depressant }\end{array}$ & No & Yes \\
\hline Rost 200Ia & $\begin{array}{l}\text { Rost et al }(2000,200 \mathrm{I}) \\
\text { Pyne et al }(2003)\end{array}$ & USA & Practice & 243 & $\begin{array}{l}\text { Adults with major } \\
\text { depression, prescribed a new } \\
\text { antidepressant, recently } \\
\text { treated }\end{array}$ & Yes & Yes \\
\hline Rost 200Ib & As above & USA & Practice & 189 & $\begin{array}{l}\text { Adults with major } \\
\text { depression, prescribed a new } \\
\text { antidepressant, beginning } \\
\text { new episode }\end{array}$ & Yes & Yes \\
\hline Simon 2000 & Simon et al (2000) & USA & Patient & 392 & $\begin{array}{l}\text { Adults with depression, } \\
\text { prescribed a new anti- } \\
\text { depressant }\end{array}$ & Yes & Yes \\
\hline Simon $2004 a$ & Simon et al (2004) & USA & Patient & 402 & $\begin{array}{l}\text { Adults with depression, } \\
\text { prescribed a new anti- } \\
\text { depressant }\end{array}$ & Yes & Yes \\
\hline Simon $2004 b$ & As above & USA & Patient & 393 & $\begin{array}{l}\text { Adults with depression, } \\
\text { prescribed a new anti- } \\
\text { depressant }\end{array}$ & Yes & Yes \\
\hline Swindle 2003 & Swindle et al (2003) & USA & Firm & 268 & $\begin{array}{l}\text { Adults with major } \\
\text { depression, dysthymia or } \\
\text { partially remitted major } \\
\text { depression }\end{array}$ & Yes & Yes \\
\hline Unutzer 2002 & $\begin{array}{l}\text { Unutzer et al } \\
(2001 a, 2003)\end{array}$ & USA & Patient & $180 \mid$ & $\begin{array}{l}\text { Elderly people with major } \\
\text { depression, dysthymia, or } \\
\text { both }\end{array}$ & Yes & Yes \\
\hline Wells 2000a & $\begin{array}{l}\text { Wells et al (2000); } \\
\text { Sherbourne et al (200 I); } \\
\text { Schoenbaum et al } \\
\text { (200I); Unutzer et al } \\
\text { (200lb); Wells et al } \\
\text { (2004) }\end{array}$ & USA & Practice & 867 & $\begin{array}{l}\text { Adults with major depression } \\
\text { or dysthymia }\end{array}$ & Yes & Yes \\
\hline Wells $2000 b$ & As above & USA & Practice & 932 & $\begin{array}{l}\text { Adults with major depression } \\
\text { or dysthymia }\end{array}$ & Yes & Yes \\
\hline Whooley 2000 & Whooley et al (2000) & USA & Practice & 331 & $\begin{array}{l}\text { Elderly people with } \\
\text { depressive symptoms }\end{array}$ & Yes & Yes \\
\hline Wilkinson 1993 & Wilkinson et al (1993) & UK & Patient & 61 & $\begin{array}{l}\text { Adults with depression, } \\
\text { prescribed a new anti- } \\
\text { depressant }\end{array}$ & Yes & Yes \\
\hline
\end{tabular}


Table 2 Intervention content variables $(n=34)$

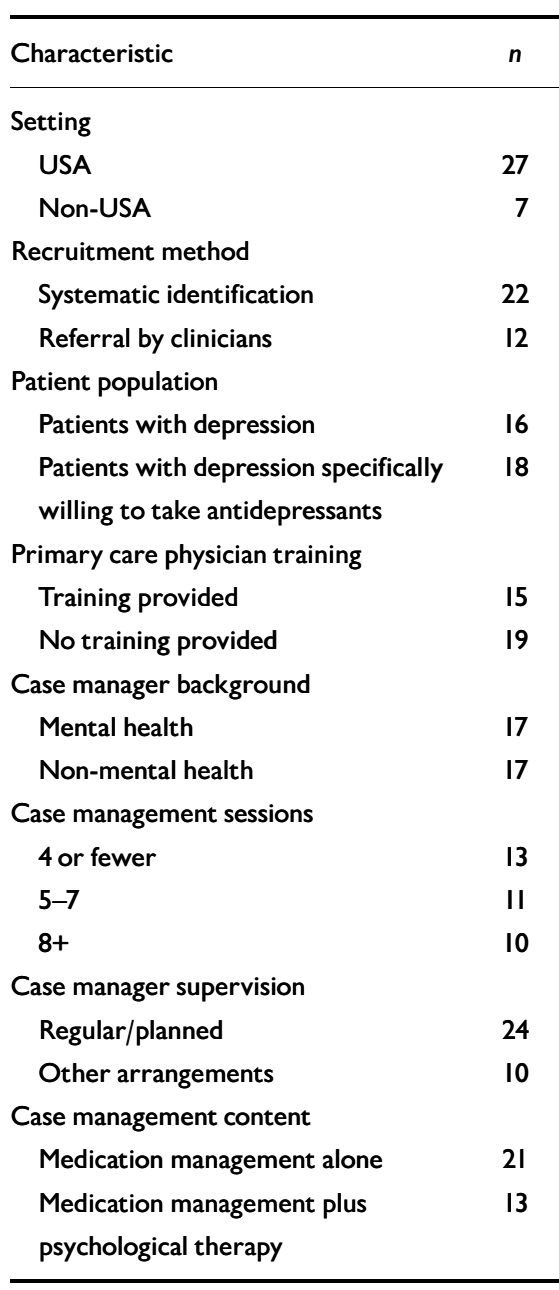

to standardised effect sizes using the logit transformation (Lipsey \& Wilson, 2001). In 5 of $62(8 \%)$ comparisons, missing data (e.g. standard deviations) were imputed from other relevant studies, in line with accepted practice (Furukawa et al, 2006).

Previous reviews have identified that unit of analysis errors are common in the evaluation of collaborative care (Gilbody et al, 2003), making studies more susceptible to type 1 errors. We identified all studies using cluster randomisation and where necessary adjusted the precision of these studies in the meta-analysis using methods recommended by the Effective Practice and Organisation of Care (EPOC) group of the Cochrane Collaboration (Bero et al, 2006) and assuming an intraclass correlation of 0.02 . The effects of adjustment for clustering were examined in a sensitivity analysis using intraclass correlations of 0.00 and 0.05 (Donner \& Klar, 2002).

\section{Analysis}

Analyses were conducted in Stata version 8 for Windows, using the metan and metareg macros. The initial meta-analyses used random effects modelling (Sutton et al, 1998) to provide an overall pooled measure of effect of collaborative care on the two outcomes. However, the main focus of the analysis was on heterogeneity. Heterogeneity was measured using the $I^{2}$ statistic, which estimates the percentage of total variation across studies that can be attributed to heterogeneity rather than chance. As a guide, $I^{2}$ values of $25 \%$ may be considered low, $50 \%$ moderate and $75 \%$ high (Higgins et al, 2003).

The main analysis used random effects meta-regression, which provided estimates of the relationships between eight intervention content variables and the two outcomes. The permutation test was used to calculate $P$ values (using 1000 Monte Carlo simulations) and to reduce the chance of spurious false-positive findings (Higgins $\&$ Thompson, 2004). The amount of heterogeneity explained by the intervention content variables was examined by reductions in the $I^{2}$ statistic. Initial univariate analyses (using a criterion of significance of $P<0.10$ ) were followed by estimation of a multivariate model. The multivariate model was not based on any automated selection procedure, but involved examination of a number of candidate models involving different combinations of variables. The final model was chosen on the basis of the greatest reduction in heterogeneity. A secondary meta-regression provided an estimate of the relationships between the two outcomes (i.e. whether antidepressant use predicted depressive symptoms).

\section{RESULTS}

We identified 28 published studies of collaborative care interventions with outcome data on antidepressant use and 34 studies with outcome data on depressive symptoms (Table 1). Intervention content variables are summarised in Table 2 .

\section{Meta-analysis}

We found a positive effect of collaborative care on antidepressant use (odds ratio 1.92, 95\% CI 1.54-2.39; Fig. 2) and depressive outcomes (standardised mean difference $0.24,95 \%$ CI 0.17-0.32; Fig. 3). The $I^{2}$ estimates of inconsistency were $80 \%$ and $54 \%$ respectively.

\section{Meta-regression}

Analyses of the effects of intervention content variables are shown in Tables 3 and 4. There was insufficient variability in quality of allocation concealment, as most studies were rated as 'not clear', and this variable was not used as a covariate in the final analysis.

None of the intervention content variables was significantly associated with antidepressant use, and no multivariate model was estimated. Three intervention content variables predicted improvement in depressive symptoms: recruitment by systematic identification $(P=0.061)$, case managers having a specific mental health background $(P=0.004)$ and provision of regular supervision for case managers $(P=0.033)$, which reduced the overall heterogeneity $I^{2}$ from $54 \%$ to $48 \%$ and 43 to $49 \%$ respectively.

In multivariate analysis, four intervention content variables produced the most robust meta-regression in relation to depressive symptom outcomes. The analysis indicated that non-US studies $(P=0.038)$, recruiting through systematic identification of patients $(P=0.081)$ and using case managers having a specific mental health background $(P=0.027)$ who received regular supervision $(P=0.055)$ were more effective. The combination of these four covariates reduced the overall heterogeneity to $36 \%$ (low to moderate between study heterogeneity). The inclusion of 'setting' (which was not statistically significant in the univariate analyses) reflects the fact that the multivariate analysis accounts for both the relationships between each intervention content variable and the outcome, and the relationships between intervention content variables (Tabachnick $\&$ Fidell, 2001).

The meta-regression of the relationships between antidepressant use and depressive symptoms showed a positive association ( $\beta$ coefficient $0.20,95 \%$ CI $0.02-0.38, P=0.028$; Fig. 4 ).

The results of these analyses were not substantively influenced by the sensitivity analysis using estimates of intracluster correlations of 0.00 and 0.05 .

\section{DISCUSSION}

Overall, the analysis showed an interesting pattern of results. No variable predicted variation in relation to our first outcome, antidepressant use. However, the study did identify several predictors of the second 


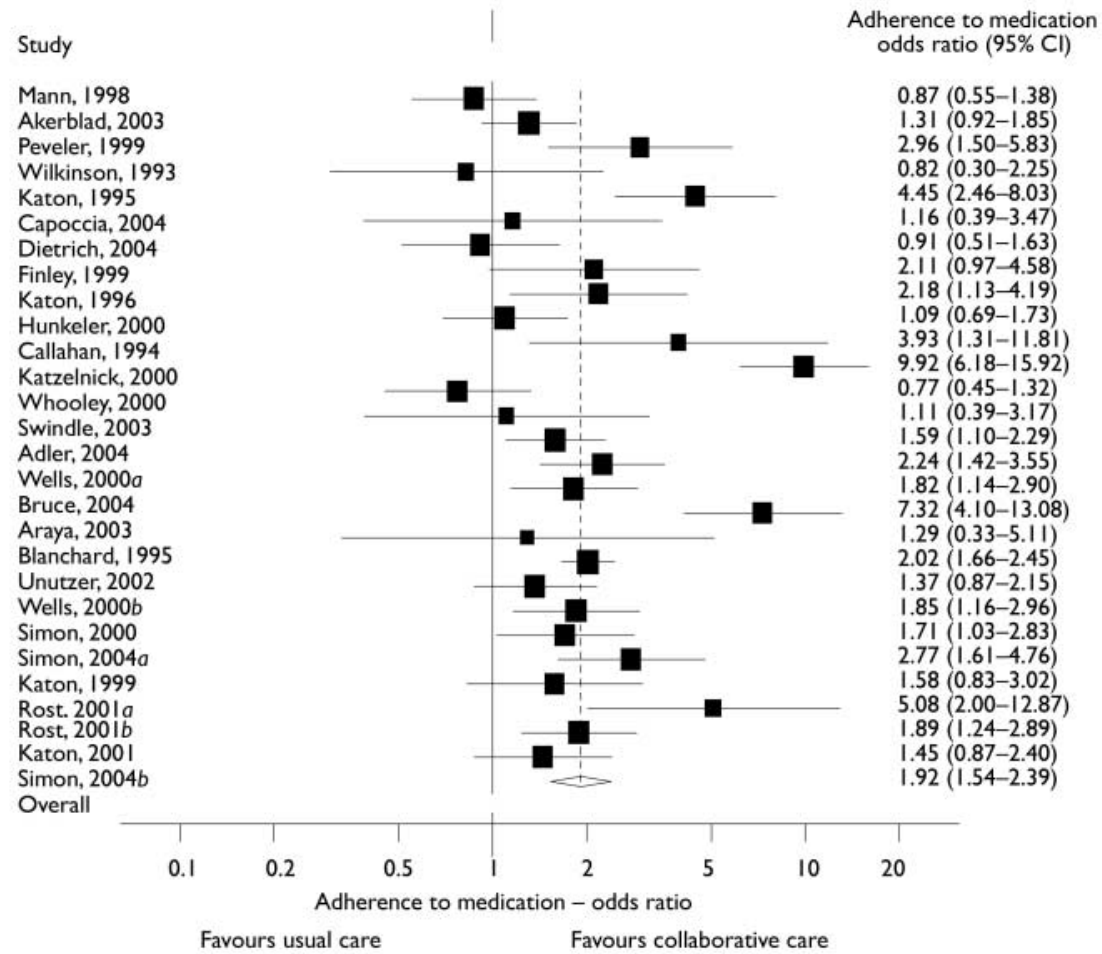

Fig. 2 Meta-analysis of antidepressant use. Note: the Wells (2000) and Simon (2004) studies involved two intervention groups compared against a single control; to avoid double-counting the controls, the sample size and event rate in the control were divided by 2 . The Rost $200 \mathrm{I}$ study data are only available analysed in two subgroups, rather than as an overall analysis; in our analysis these subgroups were treated as separate comparisons.

outcome, depressive symptoms. Furthermore, antidepressant use did predict depressive symptom outcomes, which suggests that effects of collaborative care on the latter may be mediated through changes in the former. However, it is not clear whether this association would remain significant if the antidepressant use variables were analysed alongside the other intervention content variables. Clearly the causal pathways between intervention content variables, intermediate outcomes (such as antidepressant use) and final outcomes (such as depressive symptoms) are potentially complex, and analytic techniques such as path analysis might be useful in examining these relationships further.

If the associations between intervention content variables and depressive symptom outcomes are robust, they have interesting implications for the design of collaborative care interventions. For example, the use of case managers with a mental health background and regular specialist supervision both predict outcomes, which suggests that expertise is important. This may have implications for the involvement of the new borative care models (Whitty \& Gilbody, 2005).

Clearly the meta-regression cannot determine the process by which expertise has its influence. This may relate to specific technical skills, such as knowledge of antidepressants or the effective use of psychotherapeutic techniques, or may reflect non-specific skills, such as the ability to engage with patients or to work effectively in collaboration with other professionals. Exploration of this issue might benefit from qualitative research on the nature of patient-professional and interprofessional contact in collaborative care, and the influence of context and organisational variables (Weaver et al, 2003).

However, models of care which require personnel with significant expertise are likely to be more difficult to implement in some contexts, which may limit their usefulness, reflecting the potential tension between 'efficacy' as demonstrated in trials and 'effectiveness' in routine contexts. Also, models using expert personnel may be more costly, which raises issues about trade-offs between effectiveness and cost that need to paraprofessional graduate workers in colla- be considered when designing collaborative care interventions.

\section{Limitations of the systematic review}

As a complex intervention, collaborative care defies simple definition. Our decisions about inclusion and exclusion were informed by our previous conceptual work (Bower \& Gilbody, 2005), but we took a liberal approach to inclusion precisely because the study focused on the degree to which variability in collaborative care models influenced outcomes. Clearly the inclusion or exclusion of particular studies may have important implications, and thus our findings should be considered exploratory rather than definitive. It should also be noted that most studies were conducted in the USA and the results may not generalise to other contexts. Setting was a significant predictor in the multivariate analysis.

The validity of the coding scheme used to extract data on the interventions has not been confirmed. As noted previously, there were problems of inconsistent reporting and missing data in the published studies. A significant proportion of intervention content variables could not be included as they were not reported consistently, and it is unlikely that it would have been possible to extract data on many additional issues. However, it remains possible that other variables might be more effective predictors than those included in our analyses.

The difficulties encountered in deriving a full description of the interventions echoes traditional problems with poor reporting in randomised trials. There may be a case for adopting a more standardised approach to the reporting of the content of complex interventions (equivalent to CONSORT (Consolidated Standards of Reporting Trials; Moher et al, 2001) and QUOROM (Quality of Reporting Metaanalyses; Moher et al, 1999) in order to overcome these problems. The proliferation of web-based journal archives for the presentation of data outside the word limits of the paper-based journals provides an appropriate platform. However, determining the appropriate content and structure of such standardised reports would be challenging, given the potential range of processes involved in complex interventions. 


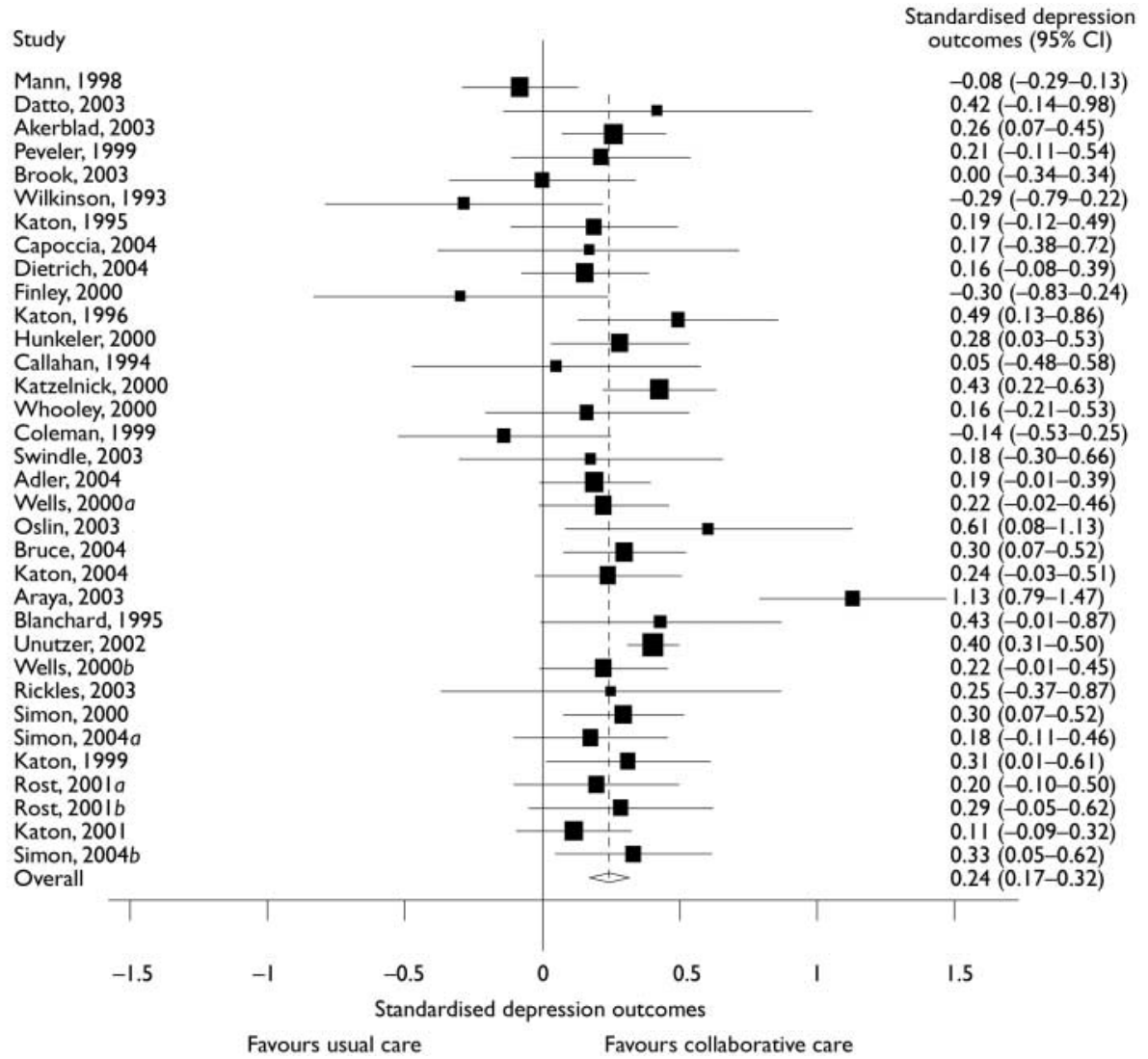

Fig. 3 Meta-analysis of depressive symptoms (see note for Fig. 2).

\section{Limitations of the meta-regression technique}

The technique of meta-regression has several limitations (Thompson \& Higgins, 2002). The analysis represents an observational association only, because meta-regression across trials does not have the benefits of randomisation. Equally, statistical power to detect useful associations using metaregression is limited by (among other things) the number of available studies (Lambert et al, 2002). Outliers may have a large influence, particularly in the context of a limited sample size. The multivariate model described earlier was found to be sensitive to the particular variables included in the analysis. It should also be noted that the analysis will not be able to detect 'active ingredients' that are necessary but do not vary between interventions. Furthermore, it is possible that with certain variables, such as the number of case management sessions, the relationship with average numbers of sessions across trials may not be the same as the relationship within trials. Only individual patient data analysis could overcome this 'ecological fallacy' (Thompson \& Higgins, 2002).

Finally, the analyses were not controlled for quality criteria. The a priori quality criterion (concealment of allocation) showed little variation, as the majority of studies failed to report this adequately. However, it is not clear whether inadequate reporting of concealment always reflects inadequate methods (Soares et al, 2004; Pildal et al, 2005).

\section{Alternatives to meta-regression in the analysis of complex interventions}

The controversy over fidelity to assertive community treatment and outcomes (Fiander et al, 2003) indicates that the identification and measurement of 'active ingredients' in mental health interventions has important implications for both research and service provision (Marshall \& Creed, 2000). It is therefore critical to consider the optimal methods of identifying 'active ingredients'. Our study has shown that the use of meta-regression is feasible but has limitations. The key issue is how well meta-regression compares with the available alternatives, which include clinical expertise, qualitative work, theoretical

Table 3 Univariate analysis of associations between intervention content variables and antidepressant use

\begin{tabular}{|c|c|c|c|c|c|}
\hline Variable & Category I & Category 2 & $\begin{array}{l}\text { Log odds ratio regression } \\
\text { coefficient }(95 \% \mathrm{Cl})\end{array}$ & $P$ & $P^{2}(\%)$ \\
\hline Study setting & Outside USA & USA & $0.076(-0.558$ to 0.710$)$ & 0.804 & 80.2 \\
\hline Patient sample & Patients with depression & $\begin{array}{l}\text { Patients with depression willing } \\
\text { to take antidepressants }\end{array}$ & $-0.123(-0.631$ to 0.385$)$ & 0.647 & 80.1 \\
\hline Recruitment method & Referral & Systematic identification & $0.345(-0.167$ to 0.858$)$ & 0.183 & 78.5 \\
\hline Primary care physician training & No training provided & Training provided & $0.328(-0.163$ to 0.818$)$ & 0.194 & 79.5 \\
\hline Case manager background & $\begin{array}{l}\text { Non-mental health } \\
\text { professional }\end{array}$ & Mental health professional & $0.220(-0.280$ to $0.72 \mathrm{I})$ & 0.393 & 78.9 \\
\hline Content of case management & Medication management & $\begin{array}{l}\text { Medication management plus } \\
\text { psychotherapeutic processes }\end{array}$ & $-0.104(-0.617$ to 0.409$)$ & 0.683 & 80.5 \\
\hline Supervision of case manager & None or variable & Regular and planned & $0.039(-0.549$ to 0.627$)$ & 0.906 & 80.4 \\
\hline Case management sessions ${ }^{\prime}$ & & & $-0.053(-0.126$ to 0.020$)$ & 0.151 & 79.6 \\
\hline
\end{tabular}

I. Number of sessions as a continuous variable (range 2-14). 
Table 4 Univariate analysis of associations between intervention content variables and depressive symptoms

\begin{tabular}{|c|c|c|c|c|c|}
\hline Variable & Category I & Category 2 & $\begin{array}{l}\text { Effect size regression } \\
\text { coefficient }(95 \% \mathrm{Cl})\end{array}$ & $P$ & $I^{2}(\%)$ \\
\hline Study setting & Outside USA & USA & $0.007(-0.193$ to 0.206$)$ & 0.930 & 54.4 \\
\hline Patient sample & Patients with depression & $\begin{array}{l}\text { Patients with depression willing } \\
\text { to take antidepressants }\end{array}$ & $-0.087(-0.243$ to 0.070$)$ & 0.285 & 52.1 \\
\hline Recruitment method & Referral & Systematic identification & $0.146(-0.014$ to 0.306$)$ & 0.061 & 47.8 \\
\hline Primary care physician training & No training provided & Training provided & $0.093(-0.065$ to 0.252$)$ & 0.237 & 54.9 \\
\hline Case manager background & $\begin{array}{l}\text { Non-mental health } \\
\text { professional }\end{array}$ & Mental health professional & $0.187 \quad$ (0.046 to 0.327$)$ & 0.004 & 42.7 \\
\hline Content of case management & Medication management & $\begin{array}{l}\text { Medication management plus } \\
\text { psychotherapeutic processes }\end{array}$ & $0.093(-0.064$ to 0.250$)$ & 0.206 & 50.7 \\
\hline Supervision of case manager & None or variable & Regular and planned & $0.169 \quad(0.002$ to 0.337$)$ & 0.033 & 49.3 \\
\hline Case management sessions' & & & $0.015(-0.008$ to 0.039$)$ & 0.174 & 50.9 \\
\hline
\end{tabular}

I. Number of sessions as a continuous variable (range 2-14).

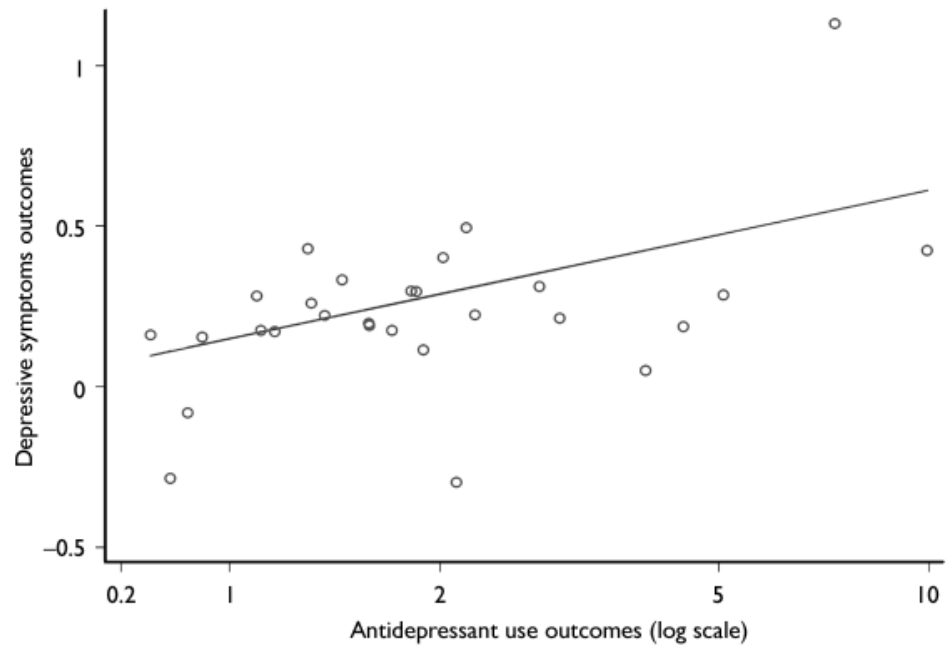

Fig. 4 Relationship between antidepressant use outcomes and depressive symptoms outcomes.

models and 'dismantling' or 'factorial' trials.

Clinical expertise is a potentially useful source of hypotheses, and rigorous qualitative work is ideally suited to capture the complexity of care processes, and is especially useful at exploring the perspectives of stakeholders and illuminating context (Weaver et al, 2003; Marshall et al, 2004). However, it is unclear whether patients and professionals can reliably identify 'active ingredients'. Acknowledgement of the limitations of clinical expertise in identifying causal mechanisms is fundamental to evidence-based medicine, and patients will presumably face many of the same challenges as professionals. Insights from theoretical models are another useful source, but few theoretical models within mental health services research are so well validated that they provide a comprehensive description of 'active ingredients', and complex mental health issues such as depression will have many competing theories. Although theory is a necessary aspect of the development of a complex intervention, it will rarely be sufficient.

Dismantling and factorial studies test different combinations of ingredients within a randomised comparison. Relevant examples exist in the collaborative care literature. For example, a recent study compared outcomes in patients randomised to a depression care programme (including systematic follow-up) and systematic follow-up alone. There was no difference in outcomes, suggesting that systematic follow-up is critical (Vergouwen et al,
2005). The advantage of such designs is that randomisation is preserved, allowing causal inference. However, the use of such costly designs to identify 'active ingredients' may not always be the optimal use of limited research resources.

Clearly comparisons of the different methods are required, and the intervention development currently being conducted by the authors also includes qualitative work which can be compared with the findings of the meta-regression. It is likely that complex interventions will increasingly be required to improve patient care within mental health, and the evaluation of such interventions raises particular challenges. Although there are potential problems with the application of meta-regression, we conclude that the technique has potential in developing useful insights into the active ingredients in complex interventions in mental health, and thus assist in the design and evaluation of future interventions.

\section{ACKNOWLEDGEMENTS}

The study was implemented in the context of research led by D.R. (funded by the Medical Research Council) in which P.B. and S.G. are grant holders. P.B. and J.F. are funded through the Department of Health, but the views expressed in this paper are those of the authors alone. P.B. thanks John Cape for useful input into the paper.

\section{REFERENCES}

Adler, D., Bungay, K., Wilson, l., et al (2004) The impact of a pharmacist intervention on 6 month outcomes in depressed primary care patients. General Hospital Psychiatry, 26, 199-209. 
Appendix Initial intervention content variables

\begin{tabular}{|c|c|}
\hline Variable & Description \\
\hline Setting & What was the geographical location of the study? \\
\hline Patient population & $\begin{array}{l}\text { Did the population include all patients with depression, or was it } \\
\text { restricted to patients who had depression and were currently taking, } \\
\text { or willing to take, antidepressants? }\end{array}$ \\
\hline Screening & $\begin{array}{l}\text { Were patients referred by their primary care providers, or systematically } \\
\text { identified (e.g. through screening)? }\end{array}$ \\
\hline \multicolumn{2}{|l|}{ Primary care providers } \\
\hline PCP professional group & What was the professional background of the primary care providers? \\
\hline PCP training and education & What training and education did the primary care providers receive? \\
\hline PCP EBM guidelines? & Did the primary care providers receive an evidence-based guideline? \\
\hline PCP T+E time & How much time was involved in the training of the primary care providers? \\
\hline PCP T+E materials & $\begin{array}{l}\text { What other materials were used in the training of the primary care } \\
\text { providers? }\end{array}$ \\
\hline \multicolumn{2}{|l|}{ Case managers } \\
\hline CM professional group & What was the professional background of the case managers? \\
\hline $\mathrm{CM}$ training and education & What training and education did the case managers receive? \\
\hline CM T+E time & How much time was involved in the training of the case managers? \\
\hline $\mathrm{CM} \mathrm{T}+\mathrm{E}$ materials & What other materials were used in the training of the case managers? \\
\hline CM session number planned & How many case management sessions were planned? \\
\hline CM session frequency planned & How often were case management sessions designed to be delivered? \\
\hline CM session duration planned & What was the planned duration of case management sessions? \\
\hline CM total time planned & What was the total planned time for the case management? \\
\hline CM session number delivered & How many case management sessions were delivered? \\
\hline CM session frequency delivered & How often were case management sessions delivered? \\
\hline CM session duration delivered & What was the actual duration of case management sessions? \\
\hline CM total time delivered & What was the actual total time for the case management? \\
\hline CM intervention content & What was the content of the case management sessions? \\
\hline $\begin{array}{l}\text { CM intervention patient } \\
\text { materials }\end{array}$ & What patient materials were used in the case management session? \\
\hline CM liaison with PCP & How did the case manager liaise with the primary care provider? \\
\hline \multicolumn{2}{|l|}{ Specialist care } \\
\hline Specialist professional group & What was the professional background of the specialist? \\
\hline Specialist training and education & What training and education did the specialist receive? \\
\hline Specialist liaison with PCP & How did the specialist liaise with the primary care provider? \\
\hline Specialist liaison with CM & How did the specialist liaise with the case manager? \\
\hline
\end{tabular}

$\mathrm{CM}$, case manager; EBM, evidence-based medicine; $\mathrm{PCP}$, primary care provider; $\mathrm{T}+\mathrm{E}$, training and education.

Araya, R., Rojas, G., Fritsch, R., et al (2003) Treating depression in primary care in low income women in Santiago, Chile: a randomised controlled trial. Lancet, 361, 995-1000.

Bero, L., Eccles, M., Grilli, R., et al (2006) About the Cochrane Collaboration (Art. No. EPOC). Cochrane Review Groups, Issue 2. Chichester: Wiley Interscience.

Bijl, D., van Marwijk, W., de Haan, M., et al (2004) Effectiveness of disease management programmes for recognition, diagnosis and treatment of depression in primary care: a review. European Journal of General Practice, 10, 6-12.

Blanchard, M., Waterreus, A. \& Mann, A. (1995) The effect of primary care nurse intervention upon older people screened as depressed. International Journal of Geriatric Psychiatry, 10, 289-298.

Boudreau, D., Capoccia, K., Sullivan, S., et al (2002) Collaborative care to improve outcomes in major depression. Annals of Pharmacotherapy, 36, 585-59I.

Bower, P. \& Gilbody, S. (2005) Managing common mental health disorders in primary care: conceptual models and evidence base. BMJ, 330, 839-842.

Bradley, F., Kinmonth, A., Mant, D., et al (1999) Development and evaluation of complex interventions in health services research: case study of the Southampton heart integrated care project (SHIP). BMI, 318, 7II-7I5.
Brook, O., van Hout, H., Nieuwenhuyse, H., et al (2003a) Effects of coaching by community pharmacists on psychological symptoms of antidepressant users: a randomised controlled trial. European

Neuropsychopharmacology, I3, 347-354.

Brook, O., van Hout, H., Nieuwenhuyse, H., et al (2003b) Impact of coaching by community pharmacists on drug attitude of depressive primary care patients and acceptability to patients: a randomized controlled trial. European Neuropsychopharmacology, 13, 1-9.

Bruce, M., Ten Have, T., Reynolds, C., et al (2004) Reducing suicidal ideation and depressive symptoms in depressed older primary care patients. JAMA, 29I, |08|-109|.

\section{Bungay, K., Adler, D., Rogers, W., et al (2004)}

Description of a clinical pharmacist intervention administered to primary care patients with depression. General Hospital Psychiatry, 26, 210-218.

Callahan, C., Hendrie, H., Dittus, R., et al (1994) Improving treatment of late life depression in primary care: a randomized clinical trial. Journal of the American Geriatrics Society, 42, 839-846.

Campbell, M., Fitzpatrick, R., Haines, A., et al (2000) Framework for design and evaluation of complex interventions to improve health. BMI, 32I, 694-696.

Capoccia, K., Boudreau, D., Blough, D., et al (2004) Randomized trial of pharmacist interventions to improve depression care and outcomes in primary care. American Journal of Health System Pharmacy, 6I, 364-372.

Coleman, E., Grothaus, L., Sandhu, N., et al (1999) Chronic care clinics: a randomized controlled trial of a new model of primary care for frail older adults. Journal of the American Geriatrics Society, 47, 775-783.

Coyne, J., Brown, G., Datto, C., et al (200I) The benefits of a broader perspective in case-finding for disease management of depression: early lessons from the PROSPECT study. International Journal of Geriatric Psychiatry, 16, 570-576.

Datto, C., Thompson, R., Horowitz, D., et al (2003) The pilot study of a telephone disease management program for depression. General Hospital Psychiatry, 25 169-177.

Dietrich, A., Oxman, T., Williams, J., et al (2004a) Going to scale: re-engineering systems for primary care treatment of depression. Annals of Family Medicine, 2. 30I-304.

Dietrich, A., Oxman, T., Williams, J., et al (2004b) Re-engineering systems for the treatment of depression in primary care: cluster randomised controlled trial. BMI 329, 605.

Donner, A. \& Klar, N. (2002) Issues in the metaanalysis of cluster randomized trials. Statistics in Medicine, 21, 2971-2980.

Fiander, M., Burns, T., McHugo, G., et al (2003) Assertive community treatment across the Atlantic: comparison of model fidelity in the UK and USA. British Journal of Psychiatry, 182, 248-254.

Finley, P., Rens, H., Gess, S., et al (1999) Case management of depression by clinical pharmacists in a primary care setting. Formulary, 34, 864-870.

Finley, P., Rens, H., Pont, J., et al (2003) Impact of a collaborative care model on depression in a primary care setting: a randomized controlled trial. Pharmacotherapy, 23, I175-1185.

Furukawa, T., Barbui, C., Cipriani, A., et al (2006) Imputing missing standard deviations in meta-analyses can provide accurate results. Journal of Clinical Epidemiology, 59, 7-10.

Gilbody, S., Whitty, P., Grimshaw, J., et al (2003) Educational and organisational interventions to improve the management of depression in primary care: a systematic review. JAMA, 289, 3|45-3I5I.

Higgins, J. \& Thompson, S. (2004) Controlling the risk of spurious findings from meta-regression. Statistics in Medicine, 23, 1663-1682.

Higgins, J., Thompson, S., Deeks, J., et al (2003) Measuring inconsistency in meta-analyses. BMJ, 327, 557-560.

Hunkeler, E., Meresman, J., Hargreaves, W., et a (2000) Efficacy of nurse telehealth care and peer support in augmenting treatment of depression in primary care. Archives of Family Medicine, 9, 700-708.

Katon, W., Von Korff, M., Lin, E., et al (1995)

Collaborative management to achieve treatment guidelines: impact on depression in primary care. JAMA, 273, |026-103|.

Katon, W., Robinson, P., Von Korff, M., et al (1996) A multifaceted intervention to improve treatment of depression in primary care. Archives of General Psychiatry, 53, 924-932.

Katon, W., Von Korff, M., Lin, E., et al (1999) Stepped collaborative care for primary care patients with persistent symptoms of depression: a randomized trial. Archives of General Psychiatry, 56, II09-1II5. 
Katon, W., Rutter, C., Ludman, E., et al (200la) A randomized trial of relapse prevention of depression in primary care. Archives of General Psychiatry, 58, 24I-247.

Katon, W., Von Korff, M., Lin, E., et al (200lb) Rethinking practitioner roles in chronic illness: the specialist, primary care physician and the practice nurse. General Hospital Psychiatry, 23, 138-144.

Katon, W., Von Korff, M., Lin, E., et al (2003) Improving primary care treatment of depression among patients with diabetes mellitus: the design of the pathways study. General Hospital Psychiatry, 25, 158-168.

Katon, W., Von Korff, M., Lin, E., et al (2004) The Pathways Study: a randomized trial of collaborative care in patients with diabetes and depression. Archives of General Psychiatry, 6I, 1042-1049.

Katzelnick, D., Simon, G., Pearson, S., et al (2000) Randomized trial of a depression management program in high utilizers of medical care. Archives of Family Medicine, 9, 345-35I.

Lambert, P., Sutton, A., Abrams, K., et al (2002) A comparison of summary patient-level covariates in metaregression with individual patient data meta-analysis. Journal of Clinical Epidemiology, 55, 86-94.

Lipsey, M. \& Wilson, D. (200I) Practical Meta-Analysis. Thousand Oaks, CA: Sage.

Loeb, M. (2002) Application of the development stages of a cluster randomized trial to a framework for evaluating complex health interventions. BMC Health Services Research, 2, 13

Mann, A., Blizard, R., Murray, J., et al (1998) An evaluation of practice nurses working with general practitioners to treat people with depression. British Journal of General Practice, 48, 875-879.

Marshall, M. \& Creed, F. (2000) Assertive community treatment - is it the future of community care in the UK? International Review of Psychiatry, 12, 191-196.

Marshall, M., Lockwood, A., Lewis, S., et al (2004) Essential elements of an early intervention service for psychosis: the opinions of expert clinicians. BMC Psychiatry, 4, 17.

Medical Research Council (2000) A Framework for Development and Evaluation of RCTs for Complex Interventions to Improve Health. London: MRC.

Moher, D., Cook, D., Eastwood, S., et al (1999) Improving the quality of reports of meta-analyses of randomised controlled trials: the QUORUM statement. Lancet, 354, 1896-1900.

Moher, D., Schutz, K. \& Altman, D. (200I) The CONSORT statement: revised recommendations for improving the quality of reports of parallel-group randomised trials. Lancet, 354, 1896-1900.

Oslin, D., Sayers, S., Ross, J., et al (2003) Disease management for depression and at risk drinking via telephone in an older population of veterans. Psychosomatic Medicine, 65, 931-937.

Peveler, R., George, C., Kinmonth, A., et al (1999) Effect of antidepressant drug counselling and information leaflets on adherence to drug treatment in primary care: randomised controlled trial. BMJ, 319, 612-615.

Pildal, J., Chan, A., Hrobjartsson, A., et al (2005) Comparisons of descriptions of allocation concealment in trial protocols and published reports: cohort study. BMJ, 330, 1049.

Pyne, J., Smith, J., Fortney, J., et al (2003) Costeffectiveness of a primary care intervention for depressed females. Journal of Affective Disorders, 74, 23-32.

Rickles, N. (2003) A Randomized Controlled Study Evaluating the Impact of an Antidepressant Monitoring

PETER BOWER, PhD, National Primary Care Research and Development Centre, University of Manchester SIMON GILBODY, DPhil, MRCPsych, DAVID RICHARDS, PhD, Department of Health Sciences, University of York; JANINE FLETCHER, MRes, Department of Nursing, Midwifery and Health Visiting, University of Manchester; ALEX SUTTON, PhD, Department of Health Sciences, University of Leicester, UK

Correspondence: Dr Peter Bower, National Primary Care Research and Development Centre, University of Manchester, Manchester MI3 9PL, UK. Email: peter.bower@manchester.ac.uk

(First received 28 February 2006, final revision 10 May 2006, accepted 2 June 2006)

Program on Consumer Outcomes. PhD Thesis, University of Wisconsin, Madison.

Rost, K., Nutting, P., Smith, J., et al (2000) Designing and implementing a primary care intervention trial to improve the quality and outcome of care for major depression. General Hospital Psychiatry, 22, 66-77.

Rost, K., Nutting, P., Smith, J., et al (200I) Improving depression outcomes in community primary care practice: a randomized trial of the QuEST intervention. Journal of General Internal Medicine, 16, 143-149.

Schoenbaum, M., Unutzer, J., Sherbourne, C., et al (200I) Cost-effectiveness of practice-initiated quality improvement for depression: results of a randomized controlled trial. JAMA, 286, 1325-1330.

Schulz, K. \& Grimes, D. (2002) Allocation concealment in randomised trials: defending against deciphering. Lancet, 359, 614-618.

Sherbourne, C., Wells, K., Duan, N., et al (200I) Long-term effectiveness of disseminating quality improvement for depression in primary care. Archives of General Psychiatry, 58, 696-703.

Simon, G. \& Von Korff, M. (1995) Recognition, management and outcomes of depression in primary care. Archives of Family Medicine, 4, 99-105.

Simon, G., Von Korff, M., Rutter, C., et al (2000) Randomised trial of monitoring, feedback and management of care by telephone to improve treatment of depression in primary care. BM/, 320, 550-554.

Simon, G., Katon, W., Von Korff, M., et al (200la) Cost-effectiveness of a collaborative care program for primary care patients with persistent depression. American Journal of Psychiatry, 158, 1638-1644.

Simon, G., Manning, W., Katzelnick, D., et al (200Ib) Cost-effectiveness of systematic depression treatment for high utilisers of general medical care. Archives of General Psychiatry, 58, 18I-187.

Simon, G., Von Korff, M., Ludman, E., et al (2002) Cost-effectiveness of a program to prevent depression relapse in primary care. Medical Care, 40, 94I-950.

Simon, G., Ludman, E., Tutty, S., et al (2004) Telephone psychotherapy and telephone care management for primary care patients starting antidepressant treatment: a randomized controlled trial. JAMA, 292, 935-942.

Soares, H., Daniels, S., Kumar, A., et al (2004) Bad reporting does not mean bad methods for randomised trials: observational study of randomised controlled trials performed by the Radiation Therapy Oncology Group. BMI, 328, 22-25.

Sutton, A., Abrams, K., Jones, D., et al (1998) Systematic reviews of trials and other studies. Health Technology Assessment, 2, I-276.

Swindle, R., Rao, J., Helmy, A., et al (2003) Integrating clinical nurse specialists into the treatment of primary care patients with depression. International Journal of Psychiatry in Medicine, 33, 17-37.
Tabachnick, B. \& Fidell, L. (200I) Using Multivariate Statistics. Boston: Allyn \& Bacon.

Thompson, S. \& Higgins, J. (2002) How should metaregression analyses be undertaken and interpreted? Statistics in Medicine, 21, 1559-1573.

Unutzer, J., Katon, W., Williams, J., et al (200la) Improving primary care for depression in late life: the design of a multicenter randomized trial. Medical Care, 39, 785-799.

Unutzer, J., Rubenstein, L., Katon, W., et al (200Ib) Two-year effects of quality improvement programs on medication management for depression. Archives of General Psychiatry, 58, 935-942.

Unutzer, J., Katon, W., Callahan, C., et al (2003) Collaborative care management of late-life depression in the primary care setting: a randomized controlled trial. JAMA, 288, 2836-2845.

Vergouwen, A., Bakker, A., Burger, H., et al (2005) A cluster randomized trial comparing two interventions to improve treatment of major depression in primary care. Psychological Medicine, 35, 25-35.

Von Korff, M. \& Goldberg, D. (200I) Improving outcomes in depression. BMJ, 323, 948-949.

Von Korff, M, Katon, W., Bush, T., et al (1998) Treatment costs, cost offset, and cost effectiveness of collaborative management of depression. Psychosomatic Medicine, 60, 143-149.

Weaver, T., Tyrer, P., Ritchie, J., et al (2003) Assessing the value of assertive outreach: qualitative study of process and outcome generation in the UK700 trial. British Journal of Psychiatry, 183, 437-445.

Weingarten, S., Henning, J., Badamgarav, E., et al (2002) Interventions used in disease management programmes for patients with chronic illnesses - which ones work? Meta-analysis of published reports. BMJ, 325, 925.

Wells, K., Sherbourne, C., Schoenbaum, M., et al (2000) Impact of disseminating quality improvement programs for depression in managed primary care: a randomized controlled trial. JAMA, 283, 212-220.

Wells, K., Sherbourne, C., Schoenbaum, M., et al (2004) Five year impact of quality improvement for depression: results of a group-level randomized controlled trial. Archives of General Psychiatry, 61, 378-386.

Whitty, P. \& Gilbody, S. (2005) NICE, but will they help people with depression? The new National Institute for Clinical Excellence depression guidelines. British Journal of Psychiatry, 186, 177-178.

Whooley, M., Stone, B. \& Soghikian, K. (2000) Randomized trial of case-finding for depression in elderly primary care patients. Journal of General Internal Medicine, 15, 293-300.

Wilkinson, G., Allen, P., Marshall, E., et al (1993) The role of the practice nurse in the management of depression in general practice: treatment adherence to antidepressant medication. Psychological Medicine, 23 229-237. 